\section{Correspondence \\ Gareth J Sanger, National Centre for Bowel Research and Surgical Innovation, 1st Floor, Abernethy Building, 2 Newark Street, London, E1 2AT, UK. E-mail: g.sanger@qmul.ac.uk}

\section{Keywords}

translational sciences; gastrointestinal; neuropharmacology; motilin; ghrelin

\section{Received}

14 September 2012

Revised

26 October 2012

Accepted

15 November 2012

\author{
G J Sanger ${ }^{1}$, Y Wang ${ }^{1}$, A Hobson ${ }^{2}$ and J Broad ${ }^{1}$ \\ ${ }^{1}$ Neurogastroenterology Group, Blizard Institute, Barts \& The London School of Medicine and \\ Dentistry, Queen Mary University of London, London, UK and ${ }^{2}$ Neurogastroenterology Diagnostic \\ Centre, Princess Grace Hospital, London, UK
}

The gastrointestinal hormone motilin has been known about for $>40$ years, but after identification of its receptor and subsequent development of new tools and methods, a reappraisal of its actions is required. Firstly, it is important to note that motilin and ghrelin receptors are members of the same family (similar genomic organization, gastrointestinal distribution and abilities to stimulate gastrointestinal motility), yet each fails to recognize the ligand of the other; and whereas ghrelin and ghrelin receptors are widespread outside the gastrointestinal tract, motilin and its receptors are largely restricted to the gastrointestinal tract. Secondly, although some studies suggest motilin has activity in rodents, most do not, and receptor pseudogenes exist in rodents. Thirdly, motilin preferentially operates by facilitating enteric cholinergic activity rather than directly contracting the muscle, despite the relatively high expression of receptor immunoreactivity in muscle. This activity is ligand-dependent, with short-lasting actions of motilin contrasting with longer-lasting actions of the non-selective and selective motilin receptor agonists erythromycin and GSK962040. Finally, the use of erythromycin (also an antibiotic drug) to treat patients requiring acceleration of gastric emptying has led to concerns over safety and potential exacerbation of antibiotic resistance. Replacement motilin receptor agonists derived from erythromycin (motilides) have been unsuccessful. New, non-motilide, small molecule receptor agonists, designed to minimize self-desensitization, are now entering clinical trials for treating patients undergoing enteral feeding or with diabetic gastroparesis. Thus, for the translational pharmacologist, the study of motilin illustrates the need to avoid overreliance on artificial systems, on structural information and on animal studies.

\title{
LINKED ARTICLES
}

This article is part of a themed section on Neuropeptides. To view the other articles in this section visit http://dx.doi.org/10.1111/bph.2013.170.issue-7

\section{Abbreviations}

ENS, enteric nervous system; GI, gastrointestinal; IBS, irritable bowel syndrome; MMC, migrating motor complex

\section{Introduction}

The gastrointestinal (GI) hormone motilin was identified over 40 years ago (Brown et al., 1973) following suggestions that a substance was released from the duodenum to increase gastric emptying (Shay and Gershon-Cohen, 1935) and gastric motor activity in denervated gastric pouches (Brown et al., 1966). Motilin is a 22-amino-acid peptide, synthesized and secreted by specific endocrine cells in the epithelia of human upper small intestine, most notably the jejunum and duodenum, with smaller amounts elsewhere, such as the gastric antrum (Christofides, 1978).

In humans, motilin is released during fasting and after eating. The hormone is also released in response to air-filled balloons (Boivin et al., 1992a) or by drinking water (Christofides, 1978), suggesting that the stimulus for its 
release after eating is mechanical, although its release may also be influenced by particular nutrients such as fat (Christofides, 1978). The amount of motilin released is not thought to be high enough to affect gastric motility in healthy individuals. However, in patients with delayed gastric emptying, it is still possible that endogenous motilin may have an effect because of the greater potential to observe stimulation (Boivin et al., 1992b; see later).

The release of motilin during fasting occurs in association with phase III of the migrating motor complex (MMC). In humans, MMC activity begins in the upper gut. It is characterized by four distinct phases. The first and longest is a period of near quiescence, followed by a period of small-amplitude contractions of irregular frequency known as phase II, and then a burst of high-amplitude propulsive contractions (phase III), which move down the intestine and terminate in the distal small intestine; phase IV is sometimes used to describe the decline of activity back to baseline (Husebye, 1999). Phase III activity is thought to help clear the stomach and intestine from any undigested material, prevent bacterial overgrowth in the upper gut and perhaps help to develop the sensation of hunger (Sanger and Lee, 2008). Studies in dogs (Nakajima et al., 2010) suggest that phase II of the MMC is caused by a gradual build-up of 5-HT, which acts at 5- $\mathrm{HT}_{4}$ receptors within the enteric nervous system (ENS) to increase contractile activity. This leads to further release of 5-HT from enterochromaffin cells, by a similar process to the release of motilin. The former acts at $5-\mathrm{HT}_{3}$ receptors to help initiate phase III activity (5- $\mathrm{HT}_{3}$ receptor antagonists reduce phase III periodicity; Wilmer et al., 1993), whereas the latter helps sustain the contractile activity in the stomach (rabbit anti-motilin serum blocks phase III activity in dog stomach; Lee et al., 1983) but not the small intestine. The reason why two different mediators are involved is unclear. Nevertheless, it is worth noting that there is a correlation between gastric MMCs and feelings of hunger (Ang et al., 2008), suggesting that the released motilin could have an additional role to enhance appetite, perhaps by releasing ghrelin (Zeitlow et al., 2010) and/or by directly activating the vagus nerve (Mochiki et al., 1997; Suzuki et al., 1998) to signal information to the brain.

Motilin acts at its own receptor (motilin receptor, previously known as GPR38; Feighner et al., 1999) and following its identification, the antibiotic drug erythromycin was found to activate the motilin receptor. Erythromycin had previously been shown to mimic the GI contractile activity of motilin in dogs (Itoh et al., 1984) and displace motilin binding to rabbit and human gastric antrum muscle (Peeters et al., 1989). Such activity explained the GI adverse events associated with its use as an antibiotic and has led to its additional use as a gastric prokinetic agent for treatment of upper GI disorders (see below). This discovery also prompted the development of related structures as non-antibiotic motilin receptor agonists and to a belief that macrolide structures and antibiotic drugs are often also motilin receptor agonists (Abu-Gharbieh et al., 2004). However, it should be noted that for many of these drugs the evidence to support this assumption is weak or absent; azithromycin has only recently been shown to activate the motilin receptor (Broad and Sanger, 2012).

To understand the functions of motilin and appraise the clinical potential of drugs acting at the motilin receptor, it is important to reassess the large and sometimes confusing lit- erature on the biology of motilin. The reassessment needs to take into account the evidence derived using the molecular and chemical tools that have recently become available. This analysis identifies species-dependent properties of motilin and distinguishes the actions of motilin from those of ghrelin. It focuses attention away from the often-studied ability of motilin to directly contract GI muscle and onto the longlasting abilities of certain motilin receptor agonists to facilitate the activities of enteric nerves and hence be of therapeutic benefit to patients requiring accelerated gastric emptying.

\section{Motilin and the motilin receptor}

\section{Association with ghrelin}

Motilin and ghrelin hormones and receptors are members of the same sub-family of GPCRs (Folwaczny et al., 2001). The structural similarities between the receptors $(52 \%$ overall amino acid identity, rising to $86 \%$ in the transmembrane domains; Folwaczny et al., 2001; Ohno et al., 2010) and their unusual genomic organization (encoded within two exons with no un-translated exons; Sanger et al., 2011), their predominantly upper GI location in distinct mucosal endocrine cells (present in highest amounts within gastric oxyntic mucosa [ghrelin] or duodenal/antrum villous epithelia [motilin]; Peeters, 2006; Sanger, 2008), their release during fasting and abilities to stimulate specific movements of the upper gut during fasting (see below) or gastric emptying of meals (Ohno et al., 2010), suggest an evolutionary linkage. Nevertheless, significant differences remain. Firstly, the receptors do not recognize the natural ligands of each other, at least so far as the human and rabbit receptors that have been studied (Dass et al., 2003; Nunoi et al., 2012). Secondly, although both hormones are released during fasting (in human duodenum and jejunum biopsies ghrelin and motilin are co-produced and stored in the same cells, suggesting co-secretion; Wierup et al., 2007) and/or in response to each other (ghrelin release stimulated by motilin; Zeitlow et al., 2010), the timings of their release differ. Thus, the release of motilin during fasting is in association with phase III of the MMC (Nakajima et al., 2010), whereas ghrelin is released in association with the desire to eat (Peeters, 2006). Furthermore, whereas the released motilin may play a role in phase III MMC activity (see Introduction), insufficient amounts of ghrelin are thought to be released to initiate such an event (although exogenously applied ghrelin can induce phase IIIlike activity) (Camilleri et al., 2009). Finally, the distribution of ghrelin outside the GI tract is considerably more widespread than that of motilin (Sanger and Lee, 2008), indicating significant additional non-GI roles for this hormone. The ability of ghrelin to promote appetite, modulate energy balance, suppress inflammation and enhance growth hormone release has, for example, led to the proposed use of ghrelin receptor agonists to treat cachexia (Ashitani et al., 2009) in addition to disorders associated with delayed gastric emptying (Peeters, 2006).

\section{Species and tissue distribution of motilin}

The actions of motilin are highly species-dependent. Most notable is the absence of a functional motilin system in rats, 
mice, guinea pigs and other rodents, where motilin and motilin receptor pseudogenes have been identified (He et al., 2010; Sanger et al., 2011); in these animals, motilin fails to elicit a response (e.g. Bassil et al., 2005). It has been suggested that the lack of a response to motilin in these animals is related to the unusual anatomy and physiology of the rodent stomach, which precludes a physical ability to vomit (Sanger et al., 2011). Differences between the actions of motilin in other non-rodent species compared to those in humans are less marked but nonetheless of great importance for correct translation of data from functional studies. For example, the dog receptor has only $71 \%$ protein identity with the human motilin receptor (Ohshiro et al., 2008), a clear difference in phylogenetic tree alignment (Sanger et al., 2011) and is less sensitive to motilin receptor agonists (by $\sim 2 \log$ units for erythromycin and GSK962040; Ohshiro et al., 2008; Leming et al., 2011). In rabbits, the receptor has $84 \%$ protein identity and similar pharmacology to the human receptor (Dass et al., 2003), yet the physiological roles of motilin are more complex and depend on the unusual digestive behaviours of this animal. Thus, the rabbit is a lagomorph, the only other mammalian order that lacks an emetic reflex and relies on re-ingestion of faeces (coprophagia) for cellulose digestion. One suggestion is that motilin has been retained during evolution to help promote defecation of the hard faecal pellets, which follow the initial excretion and re-ingestion of partly digested faeces (Costa et al., 1997; Sanger et al., 2009). Such activity contrasts with that in humans where the effects of motilin agonists on lower bowel functions have been found to vary (Jameson et al., 1992; Sharma et al., 1995; Bassotti et al., 1998; Emmanuel et al., 2004; Venkatasubramani et al., 2008).

Motilin and its receptor are found mostly within the GI tract (see Introduction). Elsewhere, their existence has rarely been detected, apart from in human thyroid and bone marrow tissues where the mRNA for the receptor has been demonstrated (Feighner et al., 1999). In addition, data obtained from measuring mRNA and immunohistochemistry suggest that motilin is also present in the brains of several species, including humans and monkeys (Yanaihara et al., 1978; Depoortere et al., 1997). However, the translation of this to functional activity has not yet been achieved; studies suggesting that motilin receptor activation may affect brain function in rats and mice (e.g. Feng et al., 2007) must be treated with caution at present, given that functional motilin receptors have not yet been detected in rats and mice (Sanger et al., 2011). Elsewhere, motilin has been reported to cause a small contraction (maximum $\sim 20 \%$ of that evoked by $\mathrm{KCl}$ ) of human coronary arteries from six patients receiving a heart transplant, but to have no effect in arteries from 3 other transplant patients and an even smaller response in three others (Maguire et al., 2004). Again, these data have yet to be translated to a general cardiovascular effect. For example, in critically ill patients, erythromycin did not change systemic blood pressure or heart rate at a dose (200 mg i.v.), which increased gastric emptying (Nguyen et al., 2006). In another study, erythromycin (300 mg p.o.) was found to induce a small reduction in systolic blood pressure (Mangoni et al., 2004). In dogs, transient hypotensive activity was evoked by $\left[\mathrm{Leu}^{13}\right]$-motilin in vivo and in vitro but, in contrast to the ability of the peptide to stimulate gastric motility, this action was not prevented by the motilin receptor antagonist GM-109 (Iwai et al., 1998). Similarly, motilin has been reported to relax precontracted porcine coronary artery muscle strips in an endothelium-dependent manner (Higuchi et al., 1994), but only at concentrations considerably higher $(>3 \mu \mathrm{M})$ than those that activate the motilin receptor in other species.

\section{Translating the functions of motilin}

Figure 1 illustrates some of the data and major issues surrounding the interpretation and translation of the results from in vitro studies with motilin.

\section{Preferential stimulation of neuronal functions within the upper gut}

The ability of motilin receptor agonists to increase gastric emptying is largely dependent on their ability to stimulate enteric, cholinergic activity. In healthy volunteers, the propulsive activity evoked by a low dose of erythromycin (40 mg) was reduced by atropine, whereas a non-propulsive, atropine-insensitive excitatory activity was observed using a higher dose $(200 \mathrm{mg}$ ) (Coulie et al., 1998). Furthermore, in human (Broad et al., 2012; Broad and Sanger, 2012) and rabbit (Van Assche et al., 1997; Dass et al., 2003; Jarvie et al., 2007; Sanger et al., 2009) isolated stomach, electricallyevoked, cholinergically-mediated contractions were greatly increased by low concentrations of motilin, erythromycin and by the selective motilin receptor agonist GSK962040 (Figure 1), whereas higher concentrations directly contracted the muscle. It is speculated that a differential activity on the cholinergic and muscular activities of the stomach explains why repeat dosing with low doses of erythromycin increases gastric emptying, whereas higher doses induce nausea and stomach cramps (Boivin et al., 2003). Similarly, a direct contractile activity on the muscle may be consistent with the ability of relatively high doses of erythromycin to increase meal-induced satiety (Cuomo et al., 2006).

The conclusion that the major therapeutic activity of motilin receptor agonists relies on facilitation of cholinergic activity is consistent with the detection of motilin receptor binding sites and antibody staining within the myenteric plexus (Miller et al., 2000; Dass et al., 2003; Takeshita et al., 2006), but appears contrary to widespread motilin receptor antibody staining over the muscle layers of the upper GI tract (Figure 1). The latter finding suggests motilin has a more important role in this muscle than within the myenteric plexus (Takeshita et al., 2006; Ter Beek et al., 2008; Broad et al., 2012). This apparent imbalance between receptor number and function may be explained by the fact that receptor functions are governed not just by their density but also by the efficiency with which they couple to their effector mechanism. Finally, it should be noted that motilin receptor agonists can also directly activate the vagus nerve (Mochiki et al., 1997; Suzuki et al., 1998) and hence have the capacity to influence upper GI functions via an additional route.

\section{Motilin receptor desensitization and long-lasting actions}

The intracellular transduction mechanism of the motilin receptor was originally discovered in rabbit native tissue 
A Human recombinant receptor

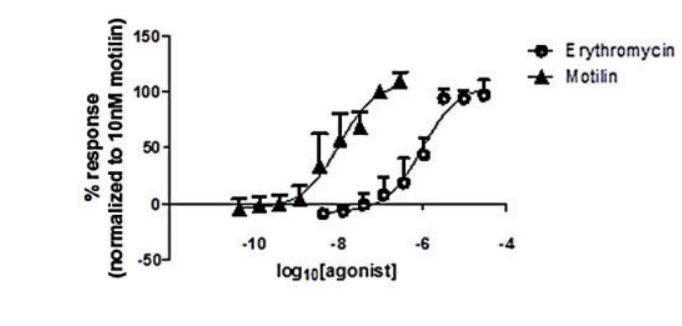

B Motilin receptor immunoreactivity in human gastric antrum
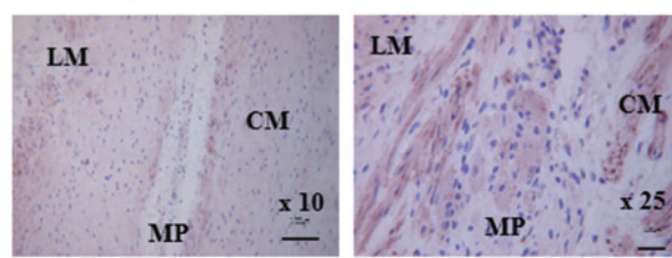

$L M, C M=$ longitudinal, circular muscle; $M P=$ myenteric plexus. $X 10$ (scale $100 \mu \mathrm{m})$ or $\times 25(125 \mu \mathrm{m})$ magnification

\section{Facilitation of cholinergically-mediated} contractions in human stomach

10nM Motilin

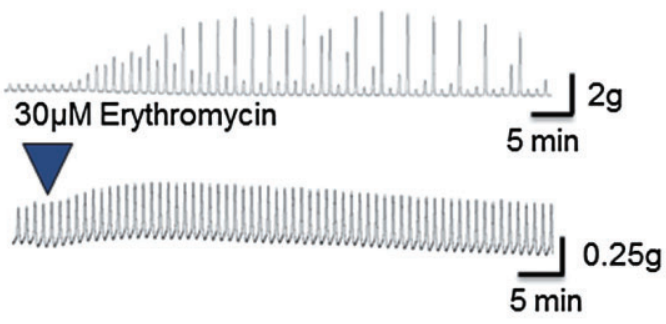

Motilin (EC $5011 \mathrm{nM} ; E_{\max }$ $109 \pm 12 \% ; t \frac{11}{2} 39 \pm 4 s$ at $100 \mathrm{nM})$ and erythromycin $\left(E C_{50} 1.0 \mu \mathrm{M} ; E_{\max } 106 \pm 7\right.$ $\% ; t 1 / 236 \pm 1$ s at $30 \mu M$ ) activate the human recombinant motilin receptor in an apparently short-lasting manner ( $n=3$ each)

Immunoreactive motilin receptors widely distributed to human stomach muscle, with limited distribution to the myenteric plexus

Expression on muscle is consistent with the ability of relatively high concentrations of motilin receptor agonists to contract gastric muscle

Low concentrations of motilin $\left(E C_{50} 33 \mathrm{nM} ; E_{\text {max }} 1041 \pm 592\right.$ $\% ; t^{1 / 2} 13 \pm 3$ min at100 nM) and erythromycin $\left(E C_{50} 1.6\right.$ $\mu M ; E_{\max } 161 \pm 97 \% ; t 1 / 232 \pm$ 4 min at $30 \mu \mathrm{M}$ ) preferentially facilitate cholinergic activity in human stomach $(\mathrm{n}=3-5 \mathrm{each})$

The pharmacology of human native motilin receptors is not clearly predicted by studies with the recombinant receptor or by immunohistochemistry

\section{Figure 1}

Data illustrating some major issues surrounding the interpretation and translation of in vitro studies with motilin. (A) Activation by motilin and erythromycin of recombinant human motilin receptors expressed in $\mathrm{CHO}$ cells, measuring changes in intracellular Ca ${ }^{2+}$. The $t_{1 / 2}$ values represent the times taken for the response to decline by $50 \%$ and are measured in $\mathrm{s}$. Data are given as the means \pm SEM of three repeat experiments. (B) Expression of motilin receptor immunoreactivity in human gastric antrum (stained in red) showing distribution of the receptor to the longitudinal and circular muscle layers of the antrum, and to the myenteric plexus; illustrations are $\times 10$ and $\times 25$. (C) Facilitation by motilin and erythromycin of cholinergically-mediated contractions of human gastric antrum circular muscle, showing differences in the duration of facilitation longer than those measured in the recombinant receptor studies. Each trace shows the actions of a submaximally effective concentration. For details on experimental methods (immunohistochemistry and human stomach), see Broad et al. (2012).

assays. Motilin receptor activation caused a rise in intracellular calcium associated with calcium release from intracellular calcium stores (Matthijs et al., 1989) via Gq-mediated inositol phosphate turnover (Depoortere and Peeters, 1995). However, with the advent of recombinant systems, motilin receptor desensitization could be investigated at the subcellular level. Much of this work was conducted in response to the failure of the motilin receptor agonist ABT229 to relieve symptoms of dyspepsia or gastroesophageal reflux disease (Talley et al., 2001). The reasons for this failure are unclear, but one possibility is that tachyphylaxis occurred, perhaps exacerbated by the $20 \mathrm{~h}$ plasma half-life and b.i.d. dosing schedule of ABT229 (Tack and Peeters, 2001). Desensitization in response to prolonged exposure to ABT229 was 
previously demonstrated in animal studies (Depoortere et al., 1999).

Motilin receptor agonist-dependent influences on $\mathrm{Ca}^{2+}$ signalling were first noted by Li et al. (2004), leading to the hypothesis that a compound with different agonist-induced intracellular trafficking may help prevent loss of efficacy with repeated dosing. In this study, motilin receptor agonists at concentrations of $1-50 \times \mathrm{EC}_{50}$ were incubated with cells expressing the motilin receptor, followed by a $5 \mathrm{~h}$ washout. The compounds were then added at $100 \times \mathrm{EC}_{50}$ concentrations and the maximum $\% \mathrm{Ca}^{2+}$ response recorded. Under these conditions, responses to motilin and erythromycin recovered completely during washout, whereas the activity of ABT229 was profoundly reduced after the second exposure to the compound. In similar experiments, using cells transfected with the motilin receptor and also by measuring the ability of motilin to directly contract rabbit isolated duodenal muscle, a pre-incubation with increasing concentrations of motilin receptor agonists, followed by washing, was used to determine the propensity of each agonist to cause tachyphylaxis (Thielemans et al., 2005). The results showed that ABT229 was 10 -fold more potent at inducing desensitization than motilin, despite being 10-fold less potent as a motilin receptor agonist. This effect was associated with a relatively high ability of ABT229 to induce receptor internalization (Lamian et al., 2006; Mitselos et al., 2008). Furthermore, there was a greater propensity of ABT229 to cause receptor phosphorylation by PKC, whereas erythromycin and motilin were phosphorylated in a PKC-independent manner (Mitselos et al., 2008). Together, these data provide a possible reason why ABT229 was unsuccessful in clinical trials and suggest that compounds with a relatively low propensity to desensitize the motilin receptor would be better candidates. Phosphorylation with PKC rather than G-protein receptor kinases is also thought to underlie differences in agonist-induced desensitization among different $\mu$-opioid receptors (for review, see Bailey et al., 2006).

Inconsistencies in the above hypothesis became apparent in studies conducted with mitemcinal. This motilide was reported to cause tachyphylaxis in rabbit duodenal muscle to a slightly greater extent than ABT229 (Carreras et al., 2004). Conversely, the desensitizing effect of mitemcinal was much less than that of ABT229 in CHO cells expressing the human motilin receptor (Takanashi and Cynshi, 2009). These results show that the desensitization profile of motilin receptor agonists can vary according to the assay. Since mitemcinal provided symptom relief in a subset of diabetic gastroparesis patients (Takanashi and Cynshi, 2009; Table 1), the translational value of each of these studies in vitro must therefore be treated with caution. This need for caution is reinforced by the very different desensitization profiles generated using motilin, erythromycin and GSK962040 in isolated stomach preparations, which measure their abilities to facilitate cholinergically-mediated contractions (see Figure 1 and below).

In rabbit gastric antrum, the ability of erythromycin to facilitate cholinergically-mediated contractions was longlasting, relative to the short-lived ability of higher concentrations of erythromycin to cause muscle contraction (Dass et al., 2003). Similar long-lasting activity was also observed with the selective motilin receptor agonist GSK962040 in human (Broad et al., 2012) and rabbit (Sanger et al., 2009) isolated stomach assays. By contrast, the ability of motilin to excite cholinergic activity was not as long-lasting, even in the presence of peptidase inhibitors and again, the direct muscle contraction was short-lived. The reasons for these different durations of activity are unknown, but it has been speculated that the existence of different agonist-dependent desensitization rates (but see earlier discussion) or different sites for motilin and non-peptide structures may be involved (see Sanger, 2008). Whatever the reason, a short-lived, intense activity of motilin, self-regulated via receptor desensitization, accords with the hypothesis that motilin might at least partly mediate phase III of the MMC. By contrast, the more maintained response to erythromycin is consistent with the ability of this drug to increase gastric emptying and provide maintained clinical benefit when given repeatedly at low doses (50-100 mg three times daily and at bedtime; DiBaise and Quigley, 1999; Dhir and Richter, 2004). Similarly, repeated dosing with GSK962040 over two weeks generated a maintained increase in gastric emptying in healthy volunteers (Dukes et al., 2010).

\section{Functions of endogenous motilin}

It is unlikely that motilin is released in sufficient amounts during eating to significantly affect gastric motility in healthy volunteers (Boivin et al., 1992b). This view appears to be consistent with the observation that the motilin receptor antagonist RWJ-68023 did not affect proximal gastric volume in healthy volunteers (Kamerling et al., 2004). However, the latter experiments should be treated with caution because even high doses of RWJ-68023 only partially prevent the ability of motilin to contract the stomach. Nevertheless, it is possible that in patients with various gut disorders, changes in motilin availability could contribute to their symptoms. For example, low blood plasma concentrations of motilin are associated with gastroesophageal reflux disease (Gadenstätter et al., 2001) and functional dyspepsia (Kusano et al., 1997). Furthermore, during a stressful interview, the release of motilin was negatively correlated with 'indigestion symptoms' (Jonsson and Hellström, 2000).

Interestingly, in dairy cattle, a specific polymorphism of the motilin gene (a single nucleotide affecting a predicted transcription factor binding site) has been shown to correlate with left-sided displacement of the abomasum (LDA; Mömke et al., 2012). This is a common disease, starting with bloating and displacement of the abomasum from the abdominal wall and may be partly governed by inheritance. It is usually preceded by decreased motility of the abomasum, impaired abomasal emptying and impaired cholinergic muscle responses. In cows undergoing surgical correction of LDA, erythromycin increases the abomasal emptying rate. Together, these observations suggest the need to further investigate a potential link between dysfunctional gastric motility and endogenous motilin.

Increased blood levels of motilin have been associated with lower bowel disorders rather than upper gut disorders. For example, increased blood levels of motilin have been reported in patients with diarrhoea- or constipation- 


\section{Table 1}

Motilin receptor agonists for treatment of disorders associated with delayed gastric emptying

\begin{tabular}{|c|c|c|c|}
\hline Compound & Structure & Profile & Clinical data \\
\hline Mitemcinal (GM-611) & Macrolide & $\begin{array}{l}\text { Mimicked ability of motilin to } \\
\text { cause short-lived contraction } \\
\text { of rabbit duodenal muscle. } \\
\text { Profiled in vivo using several } \\
\text { different animal models } \\
\text { (Takanashi and Cynshi, 2009). }\end{array}$ & $\begin{array}{l}\text { Increased gastric emptying and } \\
\text { symptomatic relief over } 3 \\
\text { months in subset of patients } \\
\text { with diabetic gastroparesis, } \\
\text { a body mass index of } \\
<35 \mathrm{~kg} \cdot \mathrm{m}^{-2} \text { and good } \\
\text { glycaemic control (McCallum } \\
\text { et al., 2007). }\end{array}$ \\
\hline GSK962040 & Small molecule & $\begin{array}{l}\text { Translation of recombinant } \\
\text { receptor data achieved using } \\
\text { human and rabbit isolated } \\
\text { stomach, demonstrating } \\
\text { long-lasting facilitation of } \\
\text { motor nerve activity (Sanger } \\
\text { et al., 2009; Broad et al., } \\
\text { 2012). }\end{array}$ & $\begin{array}{l}\text { Increased gastric emptying } \\
\text { maintained during } 14 \text { days } \\
\text { repeat dosing in healthy } \\
\text { volunteers (Dukes et al., 2009; } \\
\text { 2010) and in patients with } \\
\text { type I diabetes mellitus and } \\
\text { gastroparesis (Hellström et al., } \\
\text { 2011). }\end{array}$ \\
\hline BMS-591348 & $\begin{array}{l}\text { Small molecule/peptide hybrid; } \\
\text { structure shows example } 11 \mathrm{~A} \\
\text { from Li et al. (2004). }\end{array}$ & $\begin{array}{l}\text { Characterized as an agonist } \\
\text { using recombinant human } \\
\text { receptors (measuring changes } \\
\text { in intracellular calcium) and } \\
\text { shown to have a favourable } \\
\text { desensitization profile using a } \\
\text { cell-based tachyphylaxis assay. }\end{array}$ & None available \\
\hline RQ-00201894 & $\begin{array}{l}\text { Small molecule; structure not yet } \\
\text { disclosed. }\end{array}$ & $\begin{array}{l}\text { Active at human recombinant } \\
\text { receptor and increased gastric } \\
\text { emptying in dogs (Takahashi } \\
\text { et al., 2010). }\end{array}$ & None available \\
\hline
\end{tabular}

predominant forms of irritable bowel syndrome (IBS; Simrén et al., 2005). In addition, increased release of motilin has been reported in IBS patients undergoing psychological stress (in which colonic motility was also increased; Fukudo and Suzuki, 1987) and in constipation-predominant IBS patients receiving an infusion of intraduodenal lipids (there was a tendency for motilin concentrations to be reduced in the diarrhoea-predominant group; Simrén et al., 2001). More recently, changes in blood plasma motilin were found to co-vary with plasma concentrations of ghrelin, suggesting that if motilin has a role in the mechanisms of IBS it is likely to operate together with ghrelin (Sjölund et al., 2010). The role of motilin should now be determined by investigating the actions of a selective motilin receptor antagonist, several of which have been identified but not yet progressed to human studies (Westaway and Sanger, 2009). In dogs, the motilin receptor antagonist TZP-201 reduced anticancer chemotherapy-induced diarrhoea (Thomas et al., 2007).

\section{Erythromycin: clinical use as a motilin receptor agonist}

Erythromycin is used to induce rapid intubation or endoscopy, remove gastric contents prior to endoscopy or surgery (Levy et al., 2004; Carbonell et al., 2006), treat patients with gastroparesis (DiBaise and Quigley, 1999; Maganti et al., 2003; Ritz et al., 2005) or chronic intestinal pseudoobstruction (Emmanuel et al., 2004), treat preterm infants with food intolerance (Oei and Lui, 2001) and patients requiring facilitation of enteral feeding, and also to help diabetic patients achieve better control of blood glucose levels (Gonlachanvit et al., 2003). The doses are generally lower than those given for antibiotic use, to avoid inappropriately high stimulation of gastric emptying and tolerance to repeated dosing (Sanger, 2008). Nevertheless, this use of erythromycin is limited by its potential to exacerbate bacterial resistance (Hawkyard and Koerner, 2007), its ability to prolong the QT interval (De 
Ponti et al., 2000), with consequent increased risk of cardiac arrest, and its propensity to interact with other medications metabolized by cytochrome P450 CYP 3A4 (Okudaira et al., 2007). It should also be noted that erythromycin is not a pharmacologically selective motilin receptor agonist, as it can also inhibit purine $\mathrm{P} 2 \mathrm{X}$ receptors (at $1-10 \mu \mathrm{M}$, within the range required to activate motilin receptors; Zhao et al., 2000) and non-selectively inhibit intestinal neuromuscular functions (10-30 $\mu \mathrm{M}$; Furness et al., 1999).

\section{New motilin receptor agonists as potential drugs}

Several motilin receptor agonists, including ABT229, have been derived from the 'macrolide' structure of erythromycin (a term derived from a large macrocyclic lactone ring to which deoxy sugars are attached) and because of their ability to activate the motilin receptor, these have become known as 'motilides'. However, for different reasons (see 'Motilin receptor desensitization and long-lasting actions' for discussion on potential desensitization), most have been unsuccessful (see Sanger 2008 and Westaway \& Sanger 2009 for discussion). Difficulties in determining structure-activity relationships for such complex molecules, including achieving selectivity of action, are illustrated by the ability of ABT229 to exert activity in rats (Nieuwenhuijs et al., 1999), a species where a functional motilin receptor has not been identified (He et al., 2010; Sanger et al., 2011).

It is important to ask why motilin receptor agonists have not so far succeeded during clinical development; Table 1 lists compounds thought to be still in development. Apart from the absence of studies that ensure the molecule is not a partial agonist at the native receptor expressed by the cholinergic nerves of the human stomach and/or does not fully behave like motilin (which has only a short-lasting ability to facilitate gastric cholinergic activity), the most obvious reasons for failure relate to the selection of the correct patient population and dose of drug. The latter is especially important for motilin receptor agonists because if the dose is too high, aggressive stimulation of gastric emptying can lead to nausea and tolerance to repeated dosing. The clinical experience with relatively low and high doses of erythromycin and the lack of clinical efficacy with ABT229 both serve to exemplify this point. Most recently, GSK962040, a small molecule motilin receptor agonist able to facilitate human gastric cholinergic activity in a long-lasting manner (Broad et al., 2012), was shown to be well tolerated in healthy volunteers, accelerating gastric emptying with a favourable pharmacokinetic profile. Thus, when administered orally, it displayed dose-proportional serum concentration levels unaffected by food; the time to maximum concentration was $0.5-2.8 \mathrm{~h}$, and elimination half-life was $25.6 \mathrm{~h}$ (Dukes et al., 2009). These data suggest suitability as a once daily oral medication. In another study, the ability of GSK962040 to increase gastric emptying was maintained during a 14 day repeat-dose trial (Dukes et al., 2010).

Patients most likely to be successfully treated by a gastric prokinetic agent are those for which an increase in gastric emptying corrects a known dysfunction in motility, as opposed to patients with functional bowel disorders defined by symptoms (e.g. functional dyspepsia), in which only a subset of patients may have delayed gastric emptying (Sanger and Alpers, (2008). Disorders of gastric motility include patients in intensive care who require enteral feeding and, in many cases, an agent to stimulate gastric emptying and ensure good nutrition intake. Others include patients with diabetic gastroparesis who require better control of their blood glucose. In pilot studies, GSK962040 increased gastric emptying and improved absorption of 3-O-methylglucose in patients with enteral feed intolerance (Chapman et al., 2011) and increased gastric emptying in patients with gastroparesis and type I diabetes mellitus (Hellström et al., 2011).

\section{Lessons learnt and conclusions}

For the translational pharmacologist, the most obvious lessons are to avoid overreliance on artificial systems (e.g. recombinant receptors expressed in host cells) and on structural information (e.g. immunohistochemistry) to make accurate conclusions about the functions of a target protein. Furthermore, the term 'translational science' implies the ultimate translation of knowledge to humans, and in this process, an overreliance on animal studies can also sometimes lead to inappropriate conclusions. Each of these points is illustrated by the developing neuropharmacology of motilin. In particular, studies have highlighted liganddependent, short- and long-lasting abilities of motilin receptor agonists to facilitate gastric cholinergic activity. These activities are likely to underpin the ability of motilin to induce phase III MMC activity during fasting, as well as the ability of drugs and compounds such as erythromycin and GSK962040 to increase gastric emptying of meals over prolonged periods of repeated dosing.

At present, there are sufficient data to support a role for endogenous motilin in phase III of the MMC during fasting. However, a clear role for endogenous motilin in the mechanisms of GI disease has yet to emerge. With respect to motilin receptor agonists where issues of receptor or functional desensitization are of concern, careful selection of drugs, doses and of mechanistically appropriate patients are essential for success.

\section{Conflict of interest}

GJS and AH have received funding from GlaxoSmithKline to study the mechanisms of action and functions of the motilin receptor agonist GSK962040.

\section{References}

Abu-Gharbieh E, Vasina V, Poluzzi E, De Ponti F (2004). Antibacterial macrolides: a drug class with a complex pharmacological profile. Pharmacol Res 50: 211-222.

Ang DC, Nicolai H, Vos R, Berghe PV, Sifrim D, Depoortere I et al. (2008). Gastric phase 3 is a hunger signal in the interdigestive state in man. Gastroenterology 134 (4 Suppl. 1): A-314 (abstract). 
Ashitani J, Matsumoto N, Nakazato M (2009). Ghrelin and its therapeutic potential for cachectic patients. Peptides 30: 1951-1956.

Bailey CP, Smith FL, Kelly E, Dewey WL, Henderson G (2006). How important is protein kinase $\mathrm{C}$ in mu-opioid receptor desensitization and morphine tolerance? Trends Pharmacol Sci 27: 558-565.

Bassil A, Murray C, Dass NM, Muir A, Sanger GJ (2005). Prokineticin-2, motilin, ghrelin and metoclopramide: prokinetic utility in mouse stomach and colon. Eur J Pharmacol 524: 138-144.

Bassotti G, Chiarioni G, Vantini I, Morelli A, Whitehead WE (1998). Effect of different doses of erythromycin on colonic motility in patients with slow transit constipation. Z Gastroenterol 36: 209-213.

Boivin M, Bradette M, Raymond MC, Riberdy-Poitras M, Poitras P (1992a). Mechanisms for post-prandial release of motilin in humans. Dig Dis Sci 37: 1562-1568.

Boivin M, Riberdy M, Raymond MC, Trudel L, Poitras P (1992b). Motilin and the post-prandial motility of the antrum. Can J Physiol Pharmacol 70: 1491-1495.

Boivin MA, Carey MC, Levy H (2003). Erythromycin accelerates gastric emptying in a dose-response manner in healthy subjects. Pharmacotherapy 23: 5-8.

Broad J, Mukherjee S, Samadi M, Martin JE, Dukes GE, Sanger GJ (2012). Regional- and agonist-dependent facilitation of human neurogastrointestinal functions by motilin receptor agonists. Br J Pharmacol 167: 763-774.

Broad J, Sanger GJ (2012). The antibiotic azithromycin is a motilin receptor agonist in human stomach: Comparison with

erythromycin. Br J Pharmacol, doi: 10.1111/bph.12077.

Brown JC, Johnson LP, Magee DF (1966). Effect of duodenal alkalinization on gastric motility. Gastroenterology 50: 333-339.

Brown JC, Cook MA, Dryburgh JR (1973). Motilin, a gastric motor activity stimulating polypeptide: the complete amino acid sequence. Can J Biochem 51: 533-537.

Camilleri M, Papathanasopoulos A, Odunsi ST (2009). Actions and therapeutic pathways of ghrelin for gastrointestinal disorders. Nat Rev Gastroenterol Hepatol 6: 343-352.

Carbonell N, Pauwels A, Serfaty L, Boelle PY, Becquemont L, Poupon R (2006). Erythromycin infusion prior to endoscopy for acute upper gastrointestinal bleeding: a randomized, controlled, double-blind trial. Am J Gastroenterol 101: 1211-1215.

Carreras CW, Claypool M, Santi DV, Schuukes J, Peeters TL, Johnson RG (2004). Tachyphylaxis assays for motilin agonist drug development. Gastroenterology 126 (4 Suppl. 2): A-276.

Chapman M, Fraser R, Nguyen N, Deane A, O'Connor S, Richards D et al. (2011). The effect of GSK962040, a selective motilin agonist, on gastric emptying in critically ill patients with enteral feed intolerance. Crit Care Med 39: 195 (abstract).

Christofides ND (1978). Importance of the jejunal hormone motilin. J Clin Pathol 33 (Suppl. 8): 51-57.

Costa A, De Ponti F, Gibelli G, Crema F, d'Angelo L (1997). In vivo characterisation of the colonic prokinetic effect of erythromycin in the rabbit. Pharmacology 54: 64-75.

Coulie B, Tack J, Peeters T, Janssens J (1998). Involvement of two different pathways in the motor effects of erythromycin on the gastric antrum in humans. Gut 43: 395-400.

Cuomo R, Vandaele P, Coulie B, Peeters T, Depoortere I, Janssens J et al. (2006). Influence of motilin on gastric fundus tone and on meal-induced satiety in man: role of cholinergic pathways. Am J Gastroenterol 101: 804-811.
Dass NB, Hill J, Muir A, Testa T, Wise A, Sanger GJ (2003). The rabbit motilin receptor: molecular characterisation and pharmacology. Br J Pharmacol 140: 948-954.

De Ponti F, Poluzzi E, Montanaro N (2000). QT-interval prolongation by non-cardiac drugs: lessons to be learned from recent experience. Eur J Clin Pharmacol 56: 1-18.

Depoortere I, Peeters TL (1995). Transduction mechanism of motilin and motilides in rabbit duodenal smooth muscle. Regul Pept 55: 227-235.

Depoortere I, Van Assche G, Peeters TL (1997). Distribution and subcellular localization of motilin binding sites in the rabbit brain. Brain Res 777: 103-109.

Depoortere I, Van Assche G, Thijs T, Geboes K, Peeters TL (1999). Differential changes in ACh-, motilin-, substance P-, and $\mathrm{K}(+)$-induced contractility in rabbit colitis. Am J Physiol 277: G61-G68.

Dhir R, Richter JE (2004). Erythromycin in the short- and long-term control of dyspepsia symptoms in patients with gastroparesis. J Clin Gastroenterol 38: 237-242.

DiBaise JK, Quigley EM (1999). Efficacy of prolonged administration of intravenous erythromycin in an ambulatory setting as treatment of severe gastroparesis: one centre's experience. J Clin Gastroenterol 28: 131-134.

Dukes GE, Barton M, Dewit O, Hicks K, Vasist L, Van Hecken A et al. (2009). Pharmacokinetics, safety/tolerability, and effect on gastric emptying of the oral motilin receptor agonist, GSK962040, in healthy male and female volunteers. Neurogastroenterol Motil 21 (Suppl. 1): 84.

Dukes GE, Barton M, Dewit O, Stephens K, Vasist L, Young M et al. (2010). Safety/tolerability, pharmacokinetics (PK), and effect on gastric emptying(GE) with 14-days repeat oral dosing of the motilin receptor agonist, GSK962040, in healthy male and female volunteers. Neurogastroenterol Motil 22 (Suppl. 1): 14-15.

Emmanuel AV, Shand AG, Kamm MA (2004). Erythromycin for the treatment of chronic intestinal pseudo-obstruction: description of six cases with a positive response. Alim Pharmacol Ther 19: 687-694.

Feighner SD, Tan CP, McKee KK, Palyha OC, Hreniuk DL, Pong SS et al. (1999). Receptor for motilin identified in the human gastrointestinal system. Science 284: 2184-2188.

Feng X, Peeters TL, Tang M (2007). Motilin activates neurons in the rat amygdala and increases gastric motility. Peptides 28: 625-631.

Folwaczny C, Chang JK, Tschöp M (2001). Ghrelin and motilin: two sides of one coin? Eur J Endocrinol 144: R1-R3.

Fukudo S, Suzuki J (1987). Colonic motility, autonomic function, and gastrointestinal hormones under psychological stress on irritable bowel syndrome. Tohoku J Exp Med 151: 373-385.

Furness JB, Clark MJ, Wright T, Bertrand PP, Bornstein JC, Verlinden M (1999). An action of erythromycin in the intestine that is not mediated via motilin receptors. Clin Exp Pharmacol Physiol 26: 100-104.

Gadenstätter M, Prommegger R, Klinger A, Schwelberger H, Weiss HG, Glaser K et al. (2001). Alterations of gut neuropeptides in gastroesophageal reflux disease are resolved after antireflux surgery. Am J Surg 180: 483-487.

Gonlachanvit S, Hsu CW, Boden GH, Knight LC, Maurer AH, Fisher RS et al. (2003). Effect of altering gastric emptying on postprandial plasma glucose concentrations following a physiologic meal in type-II diabetic patients. Dig Dis Sci 48: 488-497. 
Hawkyard CV, Koerner RJ (2007). The use of erythromycin as a gastrointestinal prokinetic agent in adult critical care: benefits versus risks. J Antimicrobial Chemother 59: 347-358.

He J, Irwin DM, Chen R, Zhang Y-P (2010). Stepwise loss of motilin and its specific receptor genes in rodents. J Mol Endocrinol 44: $37-44$.

Hellström PM, Tack J, Barton ME, Stephens KE, Vasist LS, Richards DB et al. (2011). A double-blind, randomized placebo-controlled phase II study of the pharmacokinetics of single doses of the motilin agonist GSK962040, in patients with type I diabetes mellitus (TIDM) and gastroparesis. Gastroenterology 140: S183.

Higuchi Y, Nishimura J, Kanaide H (1994). Motilin induces the endothelium-dependeent relaxation of smooth muscle and the elevation of cytosolic calcium in endothelial cells in situ. Biochem Biophys Res Commun 202: 346-353.

Husebye E (1999). The patterns of small bowel motility: physiology and implications in organic disease and functional disorders. Neurogastroenterol Motil 11: 141-161.

Itoh Z, Nakaya M, Suzuki T, Arai H, Wakabayashi K (1984). Erythromycin mimics exogenous motilin in gastrointestinal contractile activity in the dog. Am J Physiol 247: G688-G694.

Iwai T, Nakamura H, Takanashi H, Yogo K, Ozaki K, Ishizuka N et al. (1998). Hypothensive mechanism of [ $\left.\mathrm{Leu}^{13}\right]$ motilin in dogs in vivo and in vitro. Can J Physiol Pharmacol 76: 1103-1109.

Jameson JS, Rogers J, Misiewicz JJ, Raimundo AH, Henry MM (1992). Oral or intravenous erythromycin has no effect on human distal colonic motility. Alim Pharmacol Ther 6: 589-595.

Jarvie EM, North Laidler V, Corcoran S, Bassil A, Sanger GJ (2007). Differences between the abilities of tegaserod and motilin receptor agonists to stimulate gastric motility in vitro. Br J Pharmacol 150: $455-462$.

Jonsson BH, Hellström PM (2000). Motilin- and neuropeptide Y-like immunoreactivity in a psychophysiological stress experiment on patients with functional dyspepsia. Integr Physiol Behav Sci 35: 256-265.

Kamerling IM, van Haarst AD, Burggraaaf J, Schoemaker RC, de Kam ML, Heinzerling $\mathrm{H}$ et al. (2004). Effects of a nonpeptide motilin receptor antagonist on proximal gastric motor function. Br J Clin Pharmacol 57: 393-401.

Kusano M, Sekiguchi T, Kawamura O, Kikuchi K, Miyazaki M, Tsunoda T et al. (1997). Further classification of dysmotility-like dyspepsia by interdigestive gastroduodenal manometry and plasma motilin level. Am J Gastroenterol 92: 481-484.

Lamian V, Rich A, Ma Z, Li J, Seethala R, Gordon D et al. (2006). Characterization of agonist-induced motilin receptor trafficking and its implications for tachyphylaxis. Mol Pharmacol 69: 109-118.

Lee KY, Chang TM, Chey WY (1983). Effect of rabbit antimotilin serum on myoelectric activity and plasma motilin concentration in fasting dog. Am J Physiol 245: G547-G553.

Leming S, Broad J, Cozens SJ, Otterson M, Winchester W, Lee K et al. (2011). GSK962040: a small molecule motilin receptor agonist which increases gastrointestinal motility in conscious dogs. Neurogastroenterol Motil 23: 958-964.

Levy H, Hayes J, Boivin M, Tomba T (2004). Transpyloric feeding tube placement in critically ill patients using electromyogram and erythromycin infusion. Chest 125: 587-591.

Li JJ, Chao H-G, Wang H, Tino JA, Lawrence RM, Ewing WR et al. (2004). Discovery of a potent and novel motilin agonist. J Med Chem 47: 1704-1708.
McCallum RW, Cynshi O, Investigator Team (2007). Efficacy of mitemcinal, a motilin receptor agonist, on gastrointestinal symptoms in patients with symptoms suggesting diabetic gastropathy: a randomized, multi-centere, placebo-controlled trial. Aliment Pharmacol Ther 26: 107-116.

Maganti K, Onyemere K, Jones MP (2003). Oral erythromycin and symptomatic relief of gastroparesis: a systematic review. Am J Gastroenterol 98: 259-263.

Maguire JJ, Kuc RE, Davenport AP (2004). Motilin mediates vasoconstriction in human coronary artery in vitro. Proc Br Pharmacol Soc. Available at: http://www.pa2online.org/ Vol2Issue2abst116P.html (accessed 4 January 2013).

Mangoni AA, Close JC, Rodriguez S, Sherwood RA, Bryant CA, Swift CG et al. (2004). Acute hypotensive effects of oral cisapride and erythromycin in healthy subjects. Br J Clin Pharmacol 58: 223-224.

Matthijs G, Peeters TL, Vantrappen G (1989). The role of intracellular calcium stores in motilin induced contractions of the longitudinal muscle of the rabbit duodenum. Naunyn Schmiedebergs Arch Pharmacol 339: 332-339.

Miller P, Roy A, St-Pierre S, Dagenais M, Lapointe R, Poitras P (2000). Motilin receptors in the human antrum. Am J Physiol 278: G18-G23.

Mitselos A, Vanden Berghe P, Peeters TL, Depoortere I (2008). Differences in motilin receptor desensitization after stimulation with motilin or motilides are due to alternative receptor trafficking. Biochem Pharmacol 75: 1115-1128.

Mochiki E, Inui A, Satoh M, Mizumoto A, Itoh Z (1997). Motilin is a biosignal controlling cyclic release of pancreatic polypeptide via the vagus in fasted dogs. Am J Physiol 272: G224-G232.

Mömke S, Sickinger M, Rehage J, Doll K, Distl O (2012). Transcription factor binding site polymorphism in the motilin gene associated with left-sided displacement of the abomasum in German Holstein cattle. PLoS ONE 7: e35562. doi:10.1371/journal.pone.0035562.

Nakajima H, Mochiki E, Zietlow A, Ludwig K, Takahashi T (2010). Mechanism of interdigestive migrating motor complex in conscious dogs. J Gastroenterol 45: 506-514.

Nguyen NQ, Mangoni AA, Fraser RJ, Chapman M, Bryant L, Burgstad C et al. (2006). Prokinetic therapy with erythromycin has no significant impact on blood pressure and heart rate in critically ill patients. Br J Clin Pharmacol 63: 498-500.

Nieuwenhuijs VB, van Duijvenbode-Beumer H, Verheem A, Visser MR, Verhoef J, Gooszen HG et al. (1999). The effects of ABT-229 and octreotide on interdigestive small bowel motility, bacterial overgrowth and bacterial translocation in rats. Eur J Clin Invest 29: 33-40.

Nunoi H, Matsuura B, Utsunomiya S, Ueda T, Miyake T, Furukawa S et al. (2012). A relationship between motilin and growth hormone secretagogue receptors. Regul Pept 176: 28-35.

Oei J, Lui K (2001). A placebo-controlled trial of low-dose erythromycin to promote feed tolerance in preterm infants. Acta Paediatr 90: 904-908.

Ohno T, Mochiki E, Kuwano H (2010). The roles of motilin and ghrelin in gastrointestinal motility. Int J Pept 2010: 1-6.

Ohshiro H, Nonaka M, Ichikawa K (2008). Molecular identification and characterization of the dog motilin receptor. Regul Pept 146: 80-87.

British Journal of Pharmacology (2013) 170 1323-1332 1331 
Okudaira T, Kotegawa T, Imai H, Tsutsumi K, Nakano S, Ohashi K (2007). Effect of the treatment period with erythromycin on cytochrome P450 3A activity in humans. J Clin Pharmacol 47: 871-876.

Peeters T, Matthijs G, Depoortere I, Cachet T, Hoogmartens J, Vantrappen G (1989). Erythromycin is a motilin receptor agonist. Am J Physiol 257: G470-G474.

Peeters TL (2006). Potential of ghrelin as a therapeutic approach for gastrointestinal motility disorders. Curr Opin Pharmacol 6: 553-558.

Ritz MA, Chapman MJ, Fraser RJ, Finnis ME, Butler RN, Cmielewski P et al. (2005). Erythromycin dose of $70 \mathrm{mg}$ accelerates gastric emptying as effectively as $200 \mathrm{mg}$ in the critically ill. Intensive Care Med 31: 949-954.

Sanger GJ (2008). Motilin, ghrelin and related neuropeptides as targets for the treatment of GI diseases. Drug Discov Today 13: 234-239.

Sanger GJ, Alpers D (2008). Development of drugs for gastrointestinal motor disorders: translating science to clinical need. Neurogastroenterol Motil 20: 177-184.

Sanger GJ, Lee K (2008). Hormones of the gut-brain axis as targets for the treatment of upper GI disorders. Nat Rev Drug Discov 7: 241-254.

Sanger GJ, Westaway SM, Barnes AA, MacPherson DT, Muir AI, Jarvie EM et al. (2009). GSK962040: a small molecule, selective motilin receptor agonist, effective as a stimulant of human and rabbit gastrointestinal motility. Neurogastroenterol Motil 21: 657-666.

Sanger GJ, Holbrook JD, Andrews PLR (2011). The translational value of rodent gastrointestinal functions: a cautionary tale. Trends Pharmacol Sci 32: 402-409.

Sharma SS, Bhargava N, Mathur SC (1995). Effect of oral erythromycin on colonic transit in patients with idiopathic constipation. A pilot study. Dig Dis Sci 40: 2446-2449.

Shay H, Gershon-Cohen J (1935). Experimental studies in gastric physiology in man: the mechanism of gastric evacuation after partial gastrectomy as demonstrated roentgenologically. Am J Dig Dis 2: 608-613.

Simrén M, Abrahamsson H, Bjornsson ES (2001). An exaggerated sensory component of the gastrocolonic response in patients with irritable bowel syndrome. Gut 48: 20-27.

Simrén M, Bjornsson ES, Abrahamsson H (2005). High interdigestive and postprandial motilin levels with the irritable bowel syndrome. Neurogastroenterol Motil 17: 51-57.

Sjölund K, Ekman R, Wierup N (2010). Covariation of plasma ghrelin and motilin in irritable bowel syndrome. Peptides 31: 1109-1112.

Suzuki H, Mochiki E, Haga N, Satoh M, Mizumoto A, Itoh Z (1998). Motilin controls cyclic release of insulin through vagal cholinergic muscarinic pathways in fasted dogs. Am J Physiol 274: G87-G95.

Tack J, Peeters T (2001). What comes after macrolides and other motilin stimulants? Gut 49: 317-318.

Takahashi N, Koba N, Yamamoto T, Sudo M (2010).

Characterization of a novel, potent and selective small molecule motilin receptor agonist, RQ-00201894. Gastroenterology 138 (5 Suppl. 1): S-713.
Takanashi H, Cynshi O (2009). Motilides: a long and winding road: lessons from mitemcinal (GM-611) on diabetic gastroparesis. Regul Pept 155: 18-23.

Takeshita E, Matsuura B, Dong M, Miller LJ, Matsui H, Onji M (2006). Molecular characterisation and distribution of motilin family receptors in the human gastrointestinal tract. J Gastroenterol 41: 223-230.

Talley NJ, Verlinden M, Geenen D, Hogan R, Riff D, McCallum R et al. (2001). Effects of a motilin receptor agonist (ABT-229) on upper gastrointestinal symptoms in type 1 diabetes mellitus: a randomised, double blind, placebo controlled trial. Gut 49: 395-401.

Ter Beek WP, Möller ESM, van den Berg M, Meijer MJ, Biemond I, Lamers CB (2008). Motilin receptor expression in smooth muscle, myenteric plexus, and mucosa of human inflamed and noninflamed intestine. Inflamm Bowel Dis 14: 612-619.

Thielemans L, Depoortere I, Perret J, Robberecht P, Liu Y, Thijs T et al. (2005). Desensitization of the human motilin receptor by motilides. J Pharmacol Exp Ther 313: 1397-1405.

Thomas H, Chen C, Marsault E (2007). The motilin receptor antagonist TZP-201 is highly effective in the control of irinotecan induced diarrhea in beagle dogs. Neurogastroenterol Motil 19 (Suppl. 3): 35 (abstract).

Van Assche G, Depoortere I, Thijs T, Janssens JJ, Peeters TL (1997). Concentration-dependent stimulation of cholinergic motor nerves or smooth muscle by $\left[\mathrm{Nle}^{13}\right]$ motilin in the isolated rabbit gastric antrum. Eur J Pharmacol 337: 267-274.

Venkatasubramani N, Rudolph CD, Sood MR (2008). Erythromycin lacks colon prokinetic effect in children with functional gastrointestinal disorders: a retrospective study. BMC Gastroenterol 8: 38 .

Westaway SM, Sanger GJ (2009). The identification and rationale for drugs which act at the motilin receptor. Prog Med Chem 48: 31-80.

Wierup N, Björkqvist M, Westrom B, Pierzynowski S, Sundler F, Sjölund K (2007). Ghrelin and motilin are cosecreted from a prominent endocrine cell population in the small intestine. J Clin Endocrinol Metab 92: 3573-3581.

Wilmer A, Tack J, Coremans G, Janssens J, Peeters T, Vantrappen G (1993). 5-hydroxytryptamine-3 receptors are involved in the initiation of gastric phase-3 motor activity in humans. Gastroenterology 105: 773-780.

Yanaihara C, Sato H, Yanaihara N, Naruse S, Forssmann WG, Helmstaedter V et al. (1978). Motilin-, substance P- and somatostatin-like immunoreactivities in extracts from dog, tupaia and monkey brain and GI tract. Adv Exp Med Biol 106: 269-283.

Zeitlow AM, Ludwig KA, Takahashi T (2010). Association between plasma ghrelin and motilin levels during interdigestive MMC cycle in conscious dogs. Gastroenterology 138 (5 Suppl. 1): S-737.

Zhao DM, Xue HH, Chida K, Suda T, Oki Y, Kanai M et al. (2000). Effect of erythromycin on ATP-induced intracellular calcium response in A549 cells. Am J Physiol 278: L726-L736. 